\title{
ELEKTRONSKO UPRAVLJANJE ODNOSIMA SA KUPCIMA MALIH I SREDNJIH PREDUZEĆA
}

\author{
ELECTRONIC CUSTOMER RELATIONSHIP \\ MANAGEMENT IN SMALL AND MEDIUM COMPANIES
}

\section{Miodrag Zlatković}

Fakultet za menadžment malih i srednjih preduzeća, Travnička 2, Beograd, Republika Srbija

\section{(C) MESTE NGO}

\section{Sažetak:}

Interaktivna priroda Web-a kombinovana sa e-mail-om predstavlja idealno okruženje u kome upravljanje tim odnosima i bazama podataka obezbeđuje osnovu za prikupljanje i čuvanje informacija o odnosima $i$ za pojačavanje odnosa putem unapređenja personalizovanih odnosa. Zbog velikih troškova upravljanja odnosima na individualnom nivou, mnoge kompanije u početnoj fazi primene CRM koriste pristup koji omogućava oblikovanje usluga za razvoj odnosa sa određenim grupama ili segmentima kupaca umesto sa pojedincima. To zahteva od kompanije da razvija dugoročne odnose sa svakom grupom kupaca da bi bolje upoznala njihove potrebe, a zatim isporučivala usluge koje zadovoljavaju te potrebe. Prema tome, upravljanje odnosima sa kupcima (CRM) uključuje set marketinških pristupa za izgradnju i održavanje dugoročnih poslova sa kupcima, u početnoj fazi razvoja sa grupama ili segmentima kupaca, a u kasnijim fazama sa pojedinačnim kupcima.

\section{Ključne reči:}

web, on-line, e-mail, informacija, upravljanje odnosima, mala i srednja preduzeća

\begin{abstract}
:
Interactive nature of the Web combined with the e-mail is the ideal environment in which management with relations and database provides the basis for collection and storage of the information about relationships and the strengthening of relations through promotion of personalized relationships. Due to the high cost of relationship management at the individual level, many companies in the initial phase of CRM applications use the approach to design services for development of relationships with certain groups of customers instead of with individuals. It requires companies to develop long term relationships with each group of customers in order to meet their needs and deliver services that meet those needs. Therefore, customer relationship management (CRM) includes a set of marketing approaches for building and maintaining long-term

Adresa autora: businesses with groups of customers in the initial phase of development, and in later stages with individual customers.
\end{abstract}

Miodrag Zlatković

䤵 m.zlatkovic@hotmail.com
Keywwords: web, on-line, e-mail, information, relationship management, SME 


\section{Uvod}

Bliski pristup upravljanju on-line odnosima sa kupcima jeste marketing za pojedinačnog kupca (one-to-one marketing) gde je upravljanje odnosima sa kupcima postavljeno na individualnoj osnovi. Zbog velikih troškova upravljanja odnosima na individualnom nivou, mnoge kompanije u početnoj fazi primene CRM koriste pristup koji omogućava oblikovanje usluga za razvoj odnosa sa određenim grupama ili segmentima kupaca umesto sa pojedincima. To zahteva od kompanije da razvija dugoročne odnose sa svakom grupom kupaca da bi bolje upoznala njihove potrebe, a zatim isporučivala usluge koje zadovoljavaju te potrebe. Prema tome, upravljanje odnosima sa kupcima (CRM) uključuje set marketinških pristupa za izgradnju i održavanje dugoročnih poslova sa kupcima, u početnoj fazi razvoja sa grupama ili segmentima kupaca, a u kasnijim fazama sa pojedinačnim kupcima.

\section{Korišćenje Interneta u merketingu odnosa}

Upravljanje odnosima sa kupcima (Customer Relationship Management, ili skraćeno CRM) obuhvata aplikacije bazirane na informacionim tehnologijama koje integrišu informacije kompanije o kupcima sa znanjem kako koristiti te informacije za efektivno kreiranje i održavanje obostrano korisnih dugoročnih odnosa. Korišćenje internet tehnologije je često označeno kao elektronsko upravljanje odnosima sa kupcima, ili skraćeno e-CRM. Elektronsko upravljanje odnosima sa kupcima, ili eCRM, uključuje integrisane baze podataka, personalizovane web pristupe bazama podataka, email i sistem toka poslovanja za ostvarivanje ciljeva CRM. Sistem toka poslovanja je često korišćen za automatizaciju procesa CRM. Na primer, sistem toka poslovanja može podsećati prodajne predstavnike kada bi trebalo kontaktirati kupce ili kako upravljati uslugama isporuke.

Slika 1. ilustruje povezanost između CRM i postojećih marketingških pristupa. Direktni marketing obezbeđuje taktike koje isporučuju marketinške komunikacije, a ponekad i same proizvode, individualnim kupcima. Teorija marketinga odnosa obezbeđuje konceptualno uobličavanje CRM ističući neophodnost povećanja usluga kupcima na osnovu boljeg poznavanja kupaca i poslovanja sa tržištima segmentiranim na individualnom nivou. Marketinška baza podataka obezbeđuje tehnološku sposobnost selekcije relevantnih podataka o kupcima koje bi trebalo čuvati i koristiti na način koji kreira strateške i taktičke marketingške mogućnosti

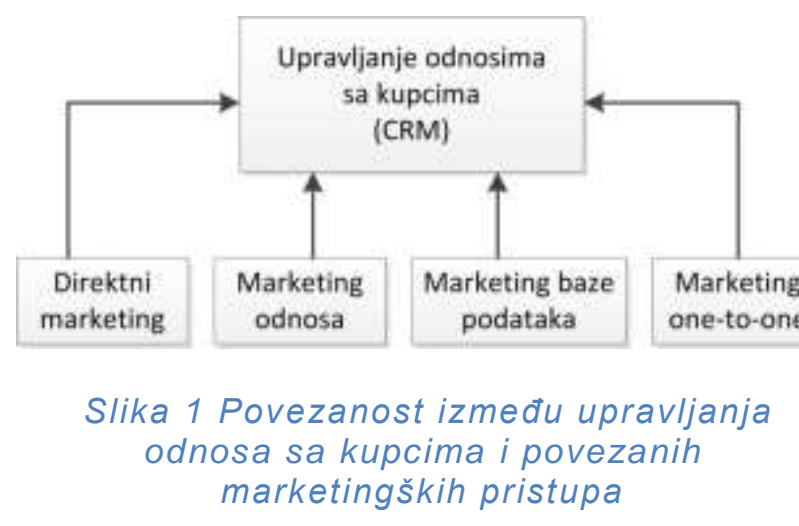

U kontekstu B-to-B poslovanja mnoge krupne kompanije često posluju sa malim brojem ponuđača, sa nekima i više dekada. Poseta krupnog značajnog kupca se često doživljava kao izuzetan događaj. (Jobber, 2001) Upravljanje ovom vrstom odnosa ima veliki uticaj na ponuđače da održavaju visok nivo usluge i pouzdanosti. Krupne i važne kupce mogu često obezbediti od dobavljača povećanu tehničku i stručnu pomoč i podršku. Pošto su takvi međusobni odnosi dugoročni, partneri mogu investirati u sistem da bi osigurali dobro komuniciranje, smanjenje rizika i veču efikasnost, kao što su programi isporuke u pravo vreme i elektronska razmena podataka. Za ponuđače ovaj sistem ima prednosti koje se, pored ostalog, ogledaju i u povećanju troškova promene dobavljača.

\section{3. Životni ciklus kupaca sa stanovišta CRM}

Faze kroz koje prolazi svaki kupac u dugoročnim odnosima pridobijanja, zadržavanja i proširenja čine životni ciklus kupca. Korelacija između izgradnje odnosa i različitih faza u životnom ciklusu kupca prikazana je na slici 2. Kako se kupac kreće kroz različite faze od pridobijanja, preko zadržavanja do proširenja, lojalnost kupca i njena vrednost za kompaniju se povećavaju. U pokušaju izgradnje Iojalnosti kupca u svakoj fazi životnog ciklusa kupca mora se početi sa identifikovanjem segmenata, a zatim odlučiti koji će segmenti biti ciljni.

Faza pridobijanja kupaca uključuje korišćenje tehnika za formiranje odnosa sa novim kupcima. Za sprovođenje kampanje regrutovanja i pridobijanja kupaca potrebno je efektivno sprovesti sedam faza:

- utvrđivanje ciljeva 
- segmentacija i profilisanje kupaca

- izbor ciljnih kupaca

- planiranje medija

- razvoj i komuniciranje ponude

- ispunjenje ponude

- analiza reagovanja kupaca.

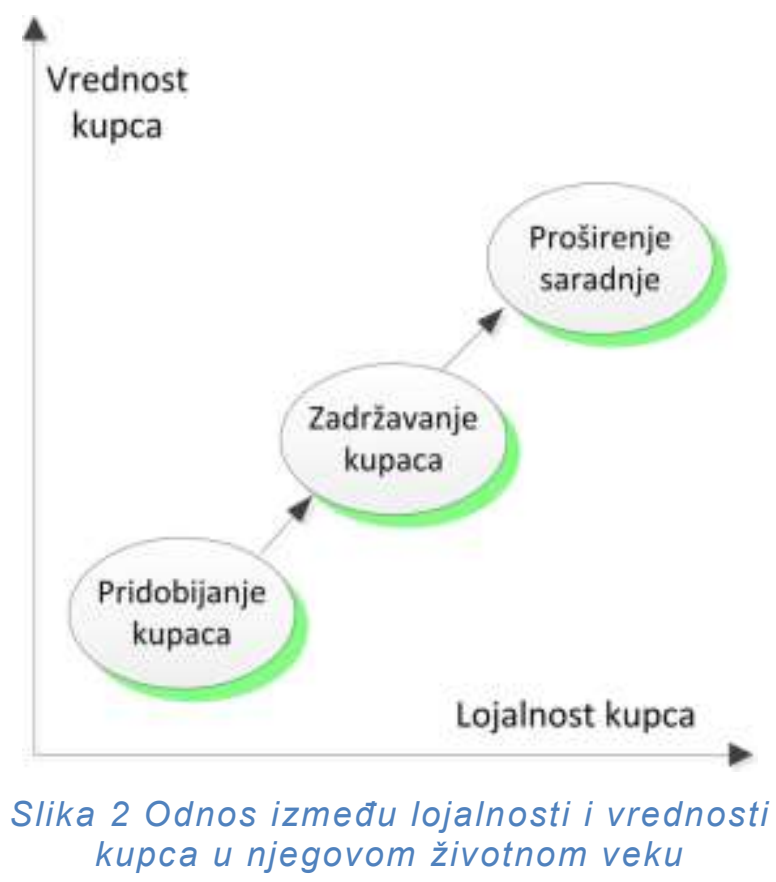

U on-line kontekstu, pridobijanje kupaca može imati dva značenja. Prvo, ono može značititi korišćenje web sajta za privlačenje novih kupaca kompanije kao kvalifikovano vođenje koje može biti prevedeno u prodaje. Kvalifikovano vođenje uključuje kontakte i informacije o profilu kupaca sa identifikovanjem njihovog nivoa interesovanja za pojedine kategorije proizvoda. On-line pridobijanje kupaca uključuje pretvaranje posetilaca sajta koji nisu kupci $u$ kandidate, a zatim u kupce. Drugo, ono može značiti podsticanje postojećih kupaca da se angažuju u online dijaloge. Mnoge organizacije se koncentrišu na bivše kupce, ali gde je pridobijanje vođeno dobro, kampanje mogu biti korišćene za ostvarivanje online konverzije posetilaca sajta u kupce. Web sajt je takođe koristan kao jevtino sredstvo za ispunjenje ponude i za analizu reagovanja kupaca. (Peppers \& Rogerson, 2001)

Faza zadržavanja kupaca uključuje akcije koje organizacija preduzima za zadržavanje postojećih kupaca. U on-line kontekstu, e-mail i direktna pošta su veoma značajni za ohrabrivanje kupaca da ponovo posete sajt i da reaguju na on-line ponudu firme.

Faza proširenja kupaca uključuje aktivnosti na povećanju dubine ili opsega proizvoda koje kupci kupuju od određene kompanije. Proširenje kupaca uključuje tehnike za ohrabrivanje kupaca da povećaju svoju saradnju sa određenom organizacijom. Na primer, on line banka može inicijalno pridobiti kupce putem korišćenja kreditnih kartica. Odnosi će biti intezivirani ako kupci mogu biti pridobijeni za kupovinu ostalih finansijskih usluga, kao što su krediti i osiguranje.

Marketari mogu, zatim, utvrditi ciljne segmente korišćenjem područja baze podataka za identifikovanje kome segmentu kupci pripadaju i korišćenjem masovne kastomizacije i personalizacije oblikovati ponudu za te kupce. Selekcija kupaca, takođe, može biti bazirana na varijacijama u on-line kupovnom ponašanju i povezana sa tipovima proizvoda. Razmatranje životnog ciklusa kupce možemo sumiranti prikazom uputstva (smernica) kako bi trebalo odrediti prioritete akcija prema različitim kupcima:

- fokus na učešće kupaca umesto na tržišno učešće, to znači povećanje prihoda od svakog kupca koliko je moguće više;

- fokus na zadržavanje kupaca, jer je ono jevtinije od pridobijanja.

- koncentracija na ponovne kupovine koje pomažu povećanju profita

- u svim fazama životnog veka kupca osluškivati njegove potrebe i reagovati na njih da bi se izgradilo poverenje i lijalni odnosi.

Ostvarivanje navedenih prioriteta u kontekstu oneto-one marketinga mora proći kroz pet osnovnih faza koje se često označavaju obrascem "5I":

- Identifikacija. Neophodno je upoznati karaktertistike kupaca što je moguće detaljnije da bi se sa njima mogao voditi dijalog. $U$ kontekstu business-to-business marketinga to znači upoznavanje svih onih koji su uključeni $u$ kupovni proces.

- Individualizacija. Individualizacija znači oblikovanje pristupa organizacije svakom kupcu, nudeći određenu korist kupcu koja je bazirana na identifikaciji potreba. Napori potrošeni na svakog kupca trebalo bi da budu konzistentni sa vrednošću koju kupci imaju za organizaciju. 
- Interakcija. Neophodan je kontinuirani dijalog za razumevanje potreba kupaca i strateške vrednosti kupaca. Interakcije moraju biti evidentirane da bi olakšale učenje odnosa.

- Integracija. Integracija odnosa i znanja o kupcima mora biti proširena na sve delove kompanije.

- Integritet. Kad svi odnosi budu izgrađeni na poverenju, najvažnije jeste održavati poverenje kupaca. Napore uložene na upoznavanje kupaca ne bi trebalo razumeti samo kao instruktivne, a privatnost kupaca mora biti zaštićena.

$\mathrm{Za}$ efektivno sprovođenje navedenih faza neophodno je obezbediti komercijalizaciju weba $u$ velikom opsegu čije karakteristike moraju biti, pored ostalih, lakoća dijaloga i odnosi centrirani na kupce.

\section{Problemi primene upravaljanja odnosima sa kupcima}

Postoje određeni problemi i teškoće koji mogu otežavati primenu upravljanja odnosima sa kupcima. Jedan od tih problema jeste nemogućnost normativnog regulisanja marketinga odnosa, jer bi u tom slučaju marketeri mogli menjati svoju strategiju samo u okvirima regulisanih univerzalnih varijanti rešenja razmene. Oni bi mogli razvijati samo univerzalne politike proizvoda i promocije za sva tržišta.

Šta ako kupci ne žele biti u određenim odnosima sa organizacijama? Zbog toga što je određena organizacija odlučila da promeni svoju strategiju marketinga odnosa, to ne znači da će i kupci, takođe, sprovesti promene $u$ istom opsegu. Kupci mogu želeti jednotransakcioni odnos u kome ne moraju trošiti velike napore za izgradnju i održavanje dugoročnih odnosa, verujući da to zavisi od ponuđača ako žele da zadrže svoje kupce. Cenovno osetljive kupce mogu jednostavno ignorisati koristi ili uštede ponuđene od brojnih ponuđača. Određene kompanije mogu videti sebe u neekonomskoj poziciji ako istovremeno koriste transakcioni i marketing odnosa sa različitim grupama kupaca. Neka istraživanja primene marketinga odnosa pokazala su da su strategije marketinga odnosa više vodile otuđivanju nego impresioniranju kupaca. lako su neke kompanije fokusirane na strategiju individualizacije i na one-to-one marketing, kupce su imale osećaj da su kompanije više posvećene bombardovanju kupaca marketinškim porukama, a manje ispunjenju svojih obećanja vezanih za proizvode i usluge.

U praksi samo mali procenat odnosa sa kupcima ima ozbiljan profitni potencijal. $U$ takvoj situaciji najteže je upravljati neprofitabilnim kupcima koji nisu pogodni kandidati za kreiranje kompleksnijih odnosa. Uprkos ovim problemima, primena marketinga odnosa smatra se veoma važnim i nezaobilaznim procesom, posebno za ponuđače tehnički složenijih proizvoda i usluga. Za lakše ostvarivanje ovog procesa potrebno je pridržavati se sledećeg redosleda u sprovođenju ključnih koraka ili faza (O'Malley \& Tynan, 2001):

- identifikovati ključne kupce

- ispitati očekivanja obeju strana (kupaca i ponuđača)

- identifikovati načine na koje kompanija može uspostaviti bliske odnose sa tim kupcima

- razmisliti o procedurama poslovanja koje bi trebalo promeniti radi olakšanja prisnijeg komuniciranja sa kupcima

- postaviti menadžera odnosa kao žižnu tačku marketinga odnosa

- biti zadovoljan sa malim dobitkom u ranijim fazama primene marketinga odnosa

- biti svestan od početka da različiti kupci imaju različite potrebe i da te razlike reflektuju načine razvoja odnosa.

\section{Marketing sa dozvolom, ili pristankom, kupaca}

Marketing sa dozvolom je značajan koncept koji učvršćuje on-line upravljanje odnosima sa kupcima. Dozvoljeni marketing je termin koji je primenio Seth Godin 1999. godine nakon sprovedenih istraživanja koja su pokazala da su kupci bombardovani dnevno sa 500 marketing poruka, a sa uključenjem weba i digitalne televizije sa 3000 poruka dnevno . Sa stanovišta marketinga organizacije to vodi u razvodnjavanje efektivnosti poruke. Sa stanovišta kupaca to vodi gubljenju njihovog strpljenja. Potrošači očekuju nagradu za njihovu pažnju, vreme i informaciju. Tradicionalni marketing kreira komunikacije koje podrivaju ili sprečavaju aktivnosti kupaca. Marketing sa dozvolom traži pristanak kupaca na saradnju pre nego što je angažuje u određene odnose i pre nego što ponudi nešto za razmenu. Za razliku od klasične razmene, businessto-business sajt može nuditi besplatna obaveštenja kupcu u razmenu za dozvolu da njegova e-mail 
adresa bude iskorišćena za održavanje međusobnog dijaloga.

Kategorija duplog pristanka postala je najprihvatljivija zbog toga što su ljudi postali sve manje tolerantni prema neodobrenim e-mail marketinškim kampanjama. Neodobrena marketinška e-mail kampanja je proces bombardovanja kupaca sa netraženim promocionim poru-kama. Drugim recima, ova kampanja uključuje istrajno saopštavanje dosadnih i iritirajućih poruka kupcima bez traženja njihove dozvole.

\section{Izgradnja on-line zajednica}

Moderna tipologija on-line poslovnih modela razlikuje veći broj različitih tipova modela. Mnogi od njih se međusobno preklapaju, neki predstavljaju elektronsku verziju postojećih tipova poslovanja, dok se neki od njih nalaze u ranoj fazi razvoja. Nema sumnje da će in u skorijoj budućnosti biti više. Sada možemo navesti sledeće (Zarić \& Bianchi, 2009):

- elektronski šoping / elektronska maloprodaja (najčešće sa B-to-C fokusom)

- elektronska nabavka (on-line nabavka dobara)

- elektronska šetališta ili aleje (grupisanje emaloprodavaca koji mogu biti upoređeni sa tradicionalnim trgovačkim centrom)

- elektronske aukcije (B-to-B ili B-to-C)

- virtuelne zajednice (grupisanje kupaca sa sličnim interesima)

- platforme saradnje (omogućavaju saradnju između kupaca ili poslovnih firmi)

- tržišta treće strane (posrednici dovode u vezu prodavce i kupce)

- integratori lanca vrednosti (ponuda određenih usluga kroz lanac vrednosti)

- informativno posredništvo (obezbeđuje informacije za potrošače ili poslovne firme)

- očuvanje poverenja i druge usluge (obezbeđuje zaštitu autentičnog kvaliteta on-line usluga)

Model on-line zajednice baziran je na komunikacionom principu "mnogi prema mnogima" za razliku od komuniciranja $u$ tradicionalnom marketingu koji je baziran na principu "jedan prema mnogima". U novom posredničkom modelu primarni odnosi nisu između pošiljaoca i primaoca, već sa kompjuterski posredovanim okruženjem sa kojim su u interakciji. (Vučenović, Zeremski, \& Lazić, 2009)

$U$ novom modelu informacije se ne prenose sa pošiljaoca na primaoca, već se formira posredovano okruženje od učesnika u kome se informacije prenose u međusobnim interakcijama.

Istraživanje stavova potrošača prema on-line zajednicama sprovedena u razvijenim zemljama pokazala su da uspešne on-line komercijalne zajednice moraju nuditi:

- kvalitetan sadržaj

- "dodatnu vrednost" interakcija

- efikasno korišćenje vremena učesnika

- jednostavan dizajn sajta koji može biti korišćen brzo

- integrisane kanale za kontaktiranje (sajt ne može biti jedini kanal)

- minimalni zahtevi u pogledu registracije ličnih podataka.

Informacije prikupljene na relevantnim sajtovima zajednice mogu obezbediti kompanijama veoma vredne podatke za različita istraživanja, uključujući i marketinška. Mnoge on-line zajednice su sada u relativno ranoj fazi razvoja i zato moraju biti predmet ozbiljnih istraživanja.

\section{Izazovi izgradnje on-line odnosa sa kupcima}

Istraživanja u razvijenom delu sveta pokazala su da postoji visok stepen verovatnoće da će se današnje poverenje $\mathrm{u}$ vlasničke mobilne mreže razviti $u$ otvorenije arhitekture koje će omogućavati kupcima izbor po želji specifičnih karakteristika usluga koje pružaju mnogi provajderi. Nove arhitekture će intezivirati konkurenciju i stimulisati dalje inovacije u ovoj dinamičnoj oblasti. Autori istih istraživanja predvideli su pojavljivanje novih entiteta koje su nazvali agentima agregacije podataka koji će se baviti ishodima privatnosti kupaca putem konsolidacije i kontrole spoljnih pristupa ličnim informacijama kupaca. Kada se kupaca jednom pojavi na sajtu za korišćenje određene on-line usluge, on će prvo izabrati agenta agregacije podataka, a zatim registrovati osnovni profil i preferalne informacije da bi dobio kustomizirani sadržaj. Kad god se bude ponovo pojavio za korišćenje usluge, on će biti povezan sa originalnim agentom agregacije podataka bez potrebe da ponovo daje svoje lične podatke. Kompanije koje imaju sistem upravljanja odnosima sa kupcima mogu koristiti podatke koje drže agenti agregacije podataka za anticipiranje potreba odabranih kupaca radi ponude kustomiziranih proizvoda $\mathrm{i}$ usluga. Ovakve mogućnosti interakcije sa kupcima 
povećaće lojalnost i osigurati da marketinški resursi budu usmereni na najbolje kupce koje nude najveće potencijale za profit.

Kompanije ne mogu obezbediti efektivan marketing odnosa ako se oslanjaju samo na službu marketinga, na koju je adresiran samo deo odnosa sa kupcima. Sa porastom interorganizacionih mreža na webu, komunikacije sa kupcima se ne svode samo na razgovor jednog kupca sa jednim ponuđačem. Za obezbeđenje usluga kojima se unapređuje lojalnost kupaca, kompanije moraju koordinirati svoje partnere i prodavce preko eksternih mreža koje olakšavaju učešće u informacijama izvan granica kompanije.

Zajedničko skladištenje podataka i zajednički instrumenti i alati za njihovu obradu olakšavaju prikukpljanje, analizu i upravljanje informacijama neophodnim za formulisanje i primenu marketinških strategija. Praktična organizacija marketinških funkcija i aktivnosti unutar internih mreža može biti veoma kompleksna. Donošenje odluka trebalo bi locirati tamo gde je i odgovornost za određene zadatke. Time se može izbeći dupliranje napora firme i konfuzija kupaca. Politika otvorenog učešća u informacijama znači da mnoštvo ishoda mora biti adresovano u pogledu "vlasništva" podataka o kupcima, uprkos tehničkim teškoćama svojstvenih integrisanim kompjuterskim sistemima koji pripadaju različitim organizacijama. Ovaj pristup označen je u literaturi kao marketing "svi sa jednim" (all-to-one). Takva integracija je često najkritičniji ishod sa kojim se sada suočavaju firme u procesu razvoja uspešne on-line strategije.

\section{Izgradnja on-line lojalnosti}

Kompanije danas troše mnogo više novca za izučavanje potrošača i razvoj strategija kojima se mogu ispunjavati individualne potrebe. Organizacije koje dobro poznaju svoje potrošače i koje mogu pridobiti njihovu lojalnost, su postale najuspešnije na današnjem konkurentnom tržištu. Međutim, vremenom kupci su postali cinični prema šemama lojalnosti koje koriste glavni supermarketi. One ne žele biti tretirane jednako, već individualno. Šta više, neke organizacije često obavljaju poslove kojima se uništavaju međusobni odnosi. $U$ okruženju multikanala kompaniji je potreban jedinstven pogled na aktivnosti kupaca da bi se dobila precizna slika o kupčevim interakcijama sa njom u slučajevima promene različitih on-line i of-line platformi. Ako su informacije nekompletne ili neprecizne, kupci će biti podozrivi prema inicijativama izgradnje odnosa, što će onemogućiti razvoj poverenja.

U okviru programa lojalnosti marketeri mogu ponuditi kupcima, pored jezgra proizvoda i usluge, dodatne specijalne usluge, niže cene, povećano komuniciranje i pažnju u zamenu za razvoj lojalnosti prema firmi, koja će firmi doneti dividende u dužem roku. Stavljanje naglaska na dugoričnim vezama sa kupcima stvara kod njih osećanje određene vrste "lične veze" sa firmom. Međutim, maloprodavci i elektronski prodavci su ustanovili da potrošači ne reaguju uvek na način koji marketinška teorija sugerira. Izučavajući kupovno ponašanje kupaca istraživači marketinga su ustanovili da mnogi potrošači prestaju da koriste potpuno iste proizvode koje koriste drugi. Oni preferiraju diferencirane proizvode koji reflektuju njihove posebne potrebe $\mathrm{i}$ želje, karakteristike ličnosti i životni stil. Kupci su postali prefinjeniji. Oni očekuju da im kompanije obezbede posebne usluge sa dodatnom vrednošću. Ako maloprodavci i e-maloprodavci ne uzimaju u obzir promenljive potrebe i zahteve kupaca, oni će jednostavno kupovati na drugim mestima. Danas je vrlo lako preći u drugu prodavnicu ili kliknuti na novi web sajt.

\section{ZAKLJUČAK}

Postoji veći broj metoda koje mogu biti korišćene za prikupljanje podataka neophodnih za personalizaciju odnosa sa kupcima. Kupci mogu dati informacije $u$ obliku odgovora na postavljena pitanja. Proverene i testirane istraživačke tehnike kao što su upitnici ili fokus grupe mogu biti korišćene on-line. Praksa registracije posetilaca može biti adaptirana tako što će pristup određenim sajtovima, ili delovima sajtova, biti dozvoljen samo onim individuama koje imaju kompletiranu inicijalnu registracionu formu. Kupci mogu obezbediti informacije o sebi angažovanjem u određenoj on-line zajednici putem analize zapisa dijaloga $u$ zajednici. Kupci mogu obezbediti informacije o sebi i kao nusproizvod određene transakcije kao što su kontakt telefon, poštanska adresa i sl. Praćenje ovih podataka tokom vremena može omogućiti sagledavanje istorije porudžbine $i$ izgradnju profila kupovnog ponašanja kupaca. Kretanje kupaca kroz web sajt može, takođe, biti praćeno. Čak i kada kupovina nije ostvarena, analiza određenih podataka može dati korisne informacije, pre svega o atraktivnosti sajta. 


\section{Citirani radovi}

Jobber, D. (2001). Principles and Practice of Marketing. Maindenhead, UK: McGraw-Hill.

O'Malley, L., \& Tynan, C. (2001). Reframing Relationship Marketing for Consumer Markets. Interactive Marketing, 2(3), 240-246.

Peppers, D., \& Rogerson, M. (2001). One to One B-to-B. New York: Capstone Publishing.

Vučenović, V., Zeremski, A., \& Lazić, J. (2009). Uspešnost menadžera. Beograd: Ekonomski institut.

Zarić, S., \& Bianchi, M. (2009). Razvoj i promocija lokalnih sistema za podršku inovativnim malim i srednjim preduzećima. Beograd - Bolonja: Benian ekonomik.

Datum prve prijave:

Datum prihvatanja članka:
20.09.2012.

16.11.2012.

\section{Kako citirati ovaj rad?}

Style - APA Sixth Edition:

Zlatković, M. (2013, 01 15). Elektronsko upravljanje odnosima sa kupcima malih i srednjih preduzeća. (Z. Čekerevac, Ed.) FBIM Transactions, 1(1), 85-91. Retrieved from www.meste.org/fbim/FBIM 1 2013/ 09.pdf. doi: 10.12709/fbim.01.01.01.09

Style - Chicago Fifteenth Edition:

Zlatković, Miodrag. "Elektronsko upravljanje odnosima sa kupcima malih i srednjih preduzeća." Edited by Zoran Čekerevac. FBIM Transactions (MESTE NVO) 1, no. 1 (01 2013): 85-91.

Style - GOST Name Sort:

Zlatković Miodrag Elektronsko upravljanje odnosima sa kupcima malih i srednjih preduzeća [Journal] = Elektronsko upravljanje odnosima sa kupcima // FBIM Transactions / ed. Čekerevac Zoran. - Beograd : MESTE NVO, 01 15, 2013. - 1 : Vol. 1. - pp. 85-91.

Style - Harvard Anglia:

Zlatković, M., 2013. Elektronsko upravljanje odnosima sa kupcima malih i srednjih preduzeća. FBIM Transactions, 15 01, 1(1), pp. 85-91.

Style - ISO 690 Numerical Reference:

Elektronsko upravljanje odnosima sa kupcima malih i srednjih preduzeća. Zlatković, Miodrag. [ed.] Zoran Čekerevac. 1, Beograd : MESTE NVO, 01 15, 2013, FBIM Transactions, Vol. 1, pp. 85-91. 